
3 Research Square
Preprints are preliminary reports that have not undergone peer review.
They should not be considered conclusive, used to inform clinical practice, or referenced by the media as validated information.

\title{
Effect of proton pump inhibitor on the movement of Helicobacter pylori across the mucus layer to the gastric lumen
}

shanshan Su(Former Corresponding Author)

Hopital Erasme Service de Gastroenterologie d'Hepato-Pancreatologie et d'Oncologie Digestive Guo-qi Zheng(New Corresponding Author) ( $\nabla$ czzxyyxhk@126.com )

Ying-ying Liu

Cangzhou Central Hospital

Yu-fei Liang

Cangzhou Central Hospital

Hui Song

Cangzhou Central Hospital

Wen-jie Yin

Cangzhou Central Hospital

Guo-zun Zhang

Cangzhou Central Hospital

Research article

Keywords: Helicobacter pylori, proton pump inhibitor, antibiotics, bismuth, pharmacological mechanism

Posted Date: December 23rd, 2019

DOI: https://doi.org/10.21203/rs.2.15795/v2

License: (c) (1) This work is licensed under a Creative Commons Attribution 4.0 International License.

Read Full License 


\section{Abstract}

Background: Helicobacter pylori ( $\mathrm{H}$. pylori ) cannot usually be detected in the gastric juice and it is thought that $\mathrm{H}$. pylori may reside under the mucus layer for long term. The mechanisms of action of proton pump inhibitor (PPI)for $\mathrm{H}$. pylori eradication are not entirely clear. Our study aimed to determine the role of PPI on the movement of $\mathrm{H}$. pylori across the mucus layer to the gastric lumen and the mechanism of PPI on $\mathrm{H}$. pylori eradication. Methods: Patients with $\mathrm{H}$. pylori infection were intravenous injected with PPI (intervention group, $n=31$ ) or without PPI (control group, $n=37$ ). The presence of $\mathrm{H}$. pylori in the gastric juice was evaluated by the rapid urease test (RUT), polymerase chain reaction (PCR), and culture methods. Results: The $\mathrm{H}$. pylori positive detection rates were all significantly higher among patients in the intervention group than among patients in the control group by the RUT $(P<0.0001)$, PCR $(\mathrm{P}<0.0001)$, and culturing $(\mathrm{P}=0.0386)$. Conclusion: $\mathrm{H}$. pylori can penetrate across the mucus layer to the gastric lumen following PPI intervention, and thus it might represent a novel target in the eradication of H. pylori .

\section{Background}

Helicobacter pylori (H. pylori) is one of the most common bacterial infections, potentially lasting for decades in an individual, and infection can lead to multiple diseases. The prevalence of $H$. pylori infection is higher than $50 \%$ in many regions of the world, for example $68.6 \%$ in Chile, $71.6 \%$ in Italy ${ }^{1}, 51.7 \%$ in Japan, $63.5 \%$ in India, and $35.6 \%$ in United States ${ }^{2}$. It ranges from $41.35 \%$ to $72.3 \%$ in China, with an average of $56.22 \%{ }^{3} \mathrm{H}$. pylori is widely regarded as one of the most common gastric pathogens ${ }^{4-}$ ${ }^{6}$ causing chronic gastritis, functional dyspepsia, peptic ulcer, gastric adenocarcinoma, and lymphoma. ${ }^{7}$,

${ }^{8}$ It has also been found to be associated with multiple extra gastrointestinal diseases, such as cardiovascular diseases, hematological system diseases, diabetes, and immune diseases. In 1994, the International Agency for Research on Cancer consensus group listed $H$. pylori as a class I human carcinogen. ${ }^{9}$ The eradication of $H$. pylori is a major global public health issue. Currently, several diagnostic tests are available for determining the presence of $H$. pylori, such as rapid urease test (RUT), histology, polymerase chain reaction (PCR), culture, urea breath test (UBT), and serology.

At present, the standard method for the eradication of $\mathrm{H}$. pylori is triple (proton pump inhibitor [PPI] + two kinds of antibiotics) or quadruple (PPI + two kinds of antibiotics + bismuth) therapy based on PPI recommended by the international guidelines from the Maastricht $\mathrm{V}$ consensus, ${ }^{10}$ the Toronto consensus, ${ }^{11}$ and other consensuses from many countries. ${ }^{12-15}$ However, using this traditional treatment, it has become increasingly difficult to eradicate $H$. pylori because of the side effects and increasing antibiotic resistance. ${ }^{16,17}$ The search for alternative treatments, such as microecological agents, traditional Chinese medicine, second-line antibiotics (such as Rifabutin), and vaccines ${ }^{18}$ has become a particular focus. However, H. pylori eradication remains a serious challenge. Until now, the mechanism of action of PPI, antibiotics, and bismuth for $H$. pylori eradication has not been fully understood. A new 
understanding of the $\mathrm{H}$. pylori eradication mechanism is needed to tailor accurate and effective H. pylori eradication therapy.

H. pylori can invade into the surface of the gastric mucosa and penetrate across the mucin layer. We therefore hypothesized that $H$. pylori may also penetrate across the mucin layer to the gastric lumen. In this study, we investigated the movement of $H$. pylori up and down the gastric mucus layer and analyzed the effect of PPI on the movement of H. pylori. .

\section{Methods}

\section{Ethical considerations}

The Ethics Committee of Central Hospital of Cangzhou City, Cangzhou, Hebei, China, approved this study, which was performed in accordance with the ethical guidelines of the Declaration of Helsinki, Good Laboratory Practices and Good Clinical Practices (2018-017-01). Written informed consent was obtained from each patient prior to study enrolment.

\section{Patients and specimens}

A total of 80 patients infected with $H$. pylori were recruited from Central Hospital of Cangzhou City from March 2018 to May 2018. H. pylori infection was diagnosed on the basis of the RUT results following gastric biopsy or a positive UBT result. Eligible patients were $\geq 18$ years of age. Subjects meeting with the following criteria were excluded: co-morbidities with severe cardiovascular disease, liver disease or other infectious disease, had received PPI or been administered histamine-2 receptor blocker (H2RB), antibiotics or other treatments that may affect $H$. pylori detection in the previous week, or had a history of gastric surgery. Patients were divided into two groups randomly: (1) Control group: patients with no previous treatment for $H$. pylori eradication, (2) Intervention group: patients who received PPI, prevacid, intravenous infusion 1-2 $\mathrm{h}$ before undergoing gastrointestinal endoscopy examination. Patients in each group did not receive any other drugs. Esophagogastroduodenoscopy was performed after an $8 \mathrm{~h}$ fast without any defrother, anesthetic or other orally-administered drugs. Patients lay on the left recumbent position of the examining table and were successfully anesthetized by intravenous injection of propofol. Then 2-3 ml of fasting gastric juice not containing blood, bile or any other components were sampled from the fundus/corpus at endoscopy by means of a sterile cannula with an external connection to a 10 $\mathrm{ml}$ sterile syringe. The $\mathrm{pH}$ of the gastric juice was determined and a Giemsa stain was performed. The gastric fluid was dropped into a RUT reagent bottle (SanQiang Biological and Chemical Co. Ltd., Fujian, China) and was observed for at least $30 \mathrm{~min}$ at room temperature. After each examination, the endoscope was washed with $2 \%$ glutaraldehyde and disinfected with $70 \%$ ethanol followed by rinsing with sterile water. The sterile cannula was reformed from a sprinkler tube by cutting off its front end, which was then washed with sterile water, treated with an enzymatic hydrolysate, and doused in glutaraldehyde for at least $10 \mathrm{~h}$, followed by rinsing with sterile water after each examination.

\section{Bacterial cultivation}


Culturing of the gastric fluid samples to detect H. pylori was performed using the Helicobacter pylori isolated, Verification and Antibiotics Susceptibility Testing Kit (Zhuhai Special Economic Zone Yimin Biological Engineering Products Factory, Zhuhai, China). The gastric fluid was inoculated onto Brucella broth supplemented with equine serum and antibiotics (vancomycin, bacillosporin, amphotericin $B$, and trimethoprim). Culture plates were incubated under microaerophilic conditions at $37^{\circ} \mathrm{C}$ and high humidity for 1-2 days. The change in color and turbidity of the culture liquid was observed, with a turbid, red culture liquid suggesting H. pylori growth (Fig. 1). Organisms were identified as $H$. pylori based on both positive catalase (Fig. 2) and urease tests (Fig. 3).

\section{PCR analysis of $H$. pylori DNA from gastric juice}

H. pylori DNA was isolated and analyzed by PCR using Diagnostic Kit of Helicobacter pylori DNA (PCRFluorescence Probing) (Daangene, Guangzhou, China) according to the manufacturer's recommendations. Take $50 \mu \mathrm{l}$ gastric juice into a $1.5 \mathrm{ml}$ centrifuge tube, add $50 \mathrm{u} 1$ purified water and $50 \mu \mathrm{l}$ DNA extract reagent into the centrifuge tube and mix it thoroughly, and then centrifuge it at 12,000 RPM for 5 minutes. Specific primers and fluorescent probes for the highly conserved coding region of $\mathrm{H}$. pylori genome as the target region were included in this kit. The reaction was performed using the $A B I 7500$ detection system (Applied Biosystems, Foster, CA, USA) with preliminary denaturation for 8 min at $50^{\circ} \mathrm{C}, 2$ min at $93^{\circ} \mathrm{C}$, followed by 10 amplification cycles of denaturation at $93^{\circ} \mathrm{C}$ for $45 \mathrm{~s}$ and annealing at $55^{\circ} \mathrm{C}$ for $1 \mathrm{~min}$, followed by 30 amplification cycles of denaturation at $93^{\circ} \mathrm{C}$ for $30 \mathrm{~s}$, annealing at $55^{\circ} \mathrm{C}$ for $45 \mathrm{~s}$, and primer extension at $55^{\circ} \mathrm{C}$ for $45 \mathrm{~s}$, with a fluorescence acquisition step at the end of the extension. The reference value for this kit was 27.02, which was determined by the ROC curve method. Samples were considered to be $H$. pylori positive when the amplification curve was of typical ' $\mathrm{S}$ ' type and the $\mathrm{Ct}$ value was $\leq 27.02$.

\section{Statistical analysis}

Calculations were performed using SPSS software version 22(IBM Corp., Armonk, NY, USA). Descriptive analysis was performed for demographic and clinical features. Results are presented as the mean \pm SD for quantitative variables and the number (percentage) for qualitative variables. The Chi-square test was used to compare categorical data. The $T$-test was used to compare normally distributed continuous variables. $P<0.05$ indicated a statistically significant difference.

\section{Results}

\section{Patients' characteristics}

Table 1 presents the patients' characteristics. The gastric fluid was collected from 68 patients infected with $H$. pylori after the gastric fluid mixed with blood or bile excluded. The $\mathrm{pH}$ value of the gastric juice was significantly higher in the intervention group than in the control group $(P<0.0001)$.

\section{Comparison of gastric fluid by the culture method}


None of the gastric fluid cultures were positive for $\mathrm{H}$. pylori in the control group (0\%), whereas four cultures positive for $H$. pylori were detected in the intervention group $(12.9 \%)$. The positive frequency was higher in the intervention group than in the control group $(P=0.0386)$.

\section{Comparison of gastric fluid by the RUT method}

Among the 37 patients in the control group, the gastric fluid sample from one patient gave a positive RUT result (2.7\%) compared with 14 positive cases among the 31 patients in the intervention group (45.2\%). The positive frequency was higher in the intervention group than in the control group $(P<0.0001)$.

\section{Comparison of gastric fluid by the PCR method}

PCR of the gastric fluid revealed six positive samples among the control group (16.2\%) compared with 20 positive samples among the intervention group (64.5\%). The positive frequency was higher in the intervention group than in the control group $(P<0.0001)$ (Fig. 4).

\section{Discussion}

H. pylori is a Gram-negative microaerobic bacterium that is spiral in shape and has 2-6 polar flagella for mobility. This bacterium resides between the surface of the gastric mucosa and the mucin layer without evidence of intracellular parasitism. ${ }^{19} \mathrm{H}$. pylori can only survive at a periplasmic $\mathrm{pH}$ of $4.0-8.5$ and can only grow at a periplasmic $\mathrm{pH}$ of $6.0-8.5$. It is difficult to detect $H$. pylori in the gastric lumen because it is such an acidic environment.

The human stomach is divided into three anatomic regions: the cardia, the fundus/corpus, and the antrum. The antrum secretes alkaline mucus $4-5 \mathrm{~cm}$ around the antrum. Therefore, $H$. pylori is mainly distributed in the antrum. ${ }^{20} \mathrm{H}$. pylori distribute in two ways: (1) by colonizing the surface of the gastric pit and epithelial cells, and (2) by colonizing above the tissue surface mucus layer. The latter is more common. An animal model revealed that $H$. pylori colonizes a zone $0-25 \mu \mathrm{m}$ above the tissue surface mucus layer, to a total thickness of about $100 \mu \mathrm{m} .{ }^{21}$ While the gastric lumen has a pH of $1-2$, a pH gradient exists across the mucus layer, reaching a pH of 6-7 at the surface of the mucosa. ${ }^{22}$ Using chemotaxis, $H$. pylori navigate this $\mathrm{pH}$ gradient to reach their niche environment near the host epithelium. 23,24

Research has revealed that the stomach supports a bacterial community comprising hundreds of phylotypes, ${ }^{25,27}$ while a pH of $<4$ prevents bacterial overgrowth. It was reported that the microbial density in the stomach is $10^{1}-10^{3} \mathrm{CFU} / \mathrm{g}^{28,29}$ This high density of bacteria means that Giemsa staining is not an optimal method for studying $H$. pylori in the stomach. Therefore, in this study, we employed the RUT, PCR analysis, and culture methods to study $H$. pylori in gastric juice.

Until now, little is known about the movement characteristics of $H$. pylori all over the world. We use PPI intervene the patients infected with $H$. pylori and study the movement characteristics of H. pylori. In this 
study, the $\mathrm{pH}$ of gastric juice in control group patients was range from 1 to 3 with an average of 1.59, which was consistent with normal $\mathrm{pH}$ value of gastric juice. The $\mathrm{pH}$ of the gastric juice of patients in the intervention group was higher than that in the control group, but $H$. pylori was detected in both groups. Culture is the gold standard method for detecting the presence of viable H. pylori. In our study, the positive detection rate was significantly higher in the gastric juice of patients in the intervention group than of patients in the control group. The RUT and PCR analysis also indicated that positive detection rates were significantly higher among patients in the intervention group than among those in the control group. The results of culturing, the RUT, and PCR were consistent. Our findings indicated that PPI intervention may induce $H$. pylori to penetrate across the mucus layer from the surface of the gastric mucosa to the gastric lumen. However, one positive case was detected by the RUT of the gastric fluid from the control group and this sample had a $\mathrm{pH}$ value of 1 , possibly indicating that the gastric fluid may be mixed with slight bile. In addition, six samples from the control group tested positive by PCR, which might indicate that there was a high load of $H$. pylori for these bacteria to be detected in the gastric lumen.

H. pylori is a fastidious microorganism that requires complex growth media. The $H$. pyloriliving environment is small in the mucus layer and a key feature of this bacterium is its microaerophilicity, with optimal growth at $\mathrm{O}_{2}$ levels of $2 \%$ to $5 \% .{ }^{30} \mathrm{H}$. pylori is unable to survival under normal atmospheric conditions or under absolute anaerobic conditions. H. pylori requires complex growth media rich in nutrients. However, the mucus layer has low permeability to most molecules such as protons, $\mathrm{O}_{2}$, and nutrient macromolecules. If the condition of juice in gastric lumen met the qualification mentioned above, H. pylori may penetrate across the mucus layer to the gastric lumen.

It is reported that PPI alone also exerts direct antimicrobial activity against $H$. pylori with $6 \%-7.7 \%$ eradication rate, ${ }^{31,32}$ which was confirmed by Meining and colleagues. ${ }^{33}$ Iwahi and coworkers ${ }^{34}$ practiced a more in-depth study of PPI, and surprisingly found that lansoprazole could inhibit the growth of $H$. pylori in vitro, similar to the antibacterial effects of antibiotics. A series of subsequent studies found that omeprazole, pantoprazole, and rabeprazole have different degrees of inhibitory effects on H. pylori in vitro, with rabeprazole showing the strongest bacteriostatic effect. However, these differing effects of PPIs have not been reported in clinic. According to our research results, we propose that PPI intervention may reduce the $\mathrm{pH}$ gradient, disturbing the $\mathrm{pH}$ chemotaxis of $H$. pylori and leading to the penetration of the mucus layer. The flagella of $H$. pylori often carry a distinctive bulb at the end. The flagella confer motility and allow rapid movement in viscous solutions such as the mucus layer overlying the gastric epithelial cells. ${ }^{35}$ Motile bacteria sense chemical gradients by means of chemoreceptor proteins, such as $\mathrm{BabA}$, with a $\mathrm{pH}$-sensor mechanism ${ }^{36}$, and relay the information to the flagellar motor ${ }^{37}$ to direct movement toward an environment with optimal concentrations of both electron acceptors and proton/electron donors. Another study reported that among $\mathrm{H}$. pylori exposed to neutral $\mathrm{pH}$, only about $7 \%$ of the culture were motile and traveled at an average speed of $10.5 \mu \mathrm{m}$ per s. By contrast, among cells that were shifted to an acidic $\mathrm{pH}, 66 \%$ were motile with a significantly faster average speed of $24.3 \mu \mathrm{m}$ per $\mathrm{s}^{38}$. It seems likely that $H$. pylori uses the $\mathrm{pH}$-sensing mechanism for orientation along the 
transmucus $\mathrm{pH}$ gradient. $H$. pylori can penetrate across the mucus layer to the gastric lumen when the $\mathrm{pH}$ gradient is reduced by PPI intervention. By the results in this study, $H$. pylori can be more easily detected in whom received intravenous PPI infusion which may imply the $H$. pylori in gastric lumen following PPI intervention. However, there are several factors involving the motility of $H$. pylori further investigation may be necessary

\section{Conclusions}

Our study indicated that $H$. pylori can penetrate the mucus layer and enter the gastric lumen where it acquires $\mathrm{O}_{2}$ and nutrients under PPI intervention. The mechanism of direct antimicrobial activity of PPI may be that PPI disturbs the pH chemotaxis of H. pylori, leading to penetration across the mucus layer, where it is diminished by probiotics above the mucus layer and eliminated by gastric emptying. Through the movement characteristic of $H$. pylori, we provide reliable data for a theoretical basis to improve the eradication of $H$. pylori.

\section{Abbreviations}

H. pylori: Helicobacter pylori; PPI: proton pump inhibitor; RUT: rapid urease test; PCR: polymerase chain reaction; UBT: urea breath test

\section{Declarations}

\section{Acknowledgments}

We are grateful to all subjects who generously provided samples for this study. A special thanks to Prof. Fu-kun Li for his precious help in the experiments performance, to Zhi-hua Xu for her help in the anesthesia of patients, and to Qing-tian Li for her help for the sterilization of the endoscope and sterile cannula.

\section{Authors' contributions}

ZGQ designed the study and the study protocol, and modified the paper. SSS and LYY performed the experiments and analyzed the data. SS wrote the paper. LYF and SH performed gastrointestinal endoscopy examination. YWJ and ZGZ collected the cases.

\section{Funding}

This work was supported by Cangzhou Health Research Fund under Grant. The funding body supported the data collection used in this study. The funding body has no role in the design of the study and 
analysis and interpretation of data and in writing the manuscript.

\section{Availability of data and material}

The datasets used and/or analysed during the current study available from the corresponding author on reasonable request.

\section{Ethics approval and consent to participate}

The Ethics Committee of Central Hospital of Cangzhou City, Cangzhou, Hebei, China, approved this study, which was performed in accordance with the ethical guidelines of the Declaration of Helsinki, Good Laboratory Practices and Good Clinical Practices (2018-017-01). Written informed consent was obtained from each patient prior to study enrolment.

\section{Consent for publication}

Not Applicable.

\section{Competing interests}

The authors declare no competing interest.

\section{Reference}

1. Mentis A, Lehours P, Mégraud F. Epidemiology and Diagnosis of Helicobacter pylori infection. Helicobacter. 2015; 20 Suppl 1:1-7.

2. Hooi JKY, Lai WY, Ng WK, Suen MMY, Underwood FE, Tanyingoh D, Malfertheiner P, Graham DY, Wong VWS, Wu JCY, Chan FKL, Sung JJY, Kaplan GG, Ng SC. Global Prevalence of Helicobacter pylori Infection: Systematic Review and Meta-Analysis. Gastroenterology. 2017; 153(2): 420-429..

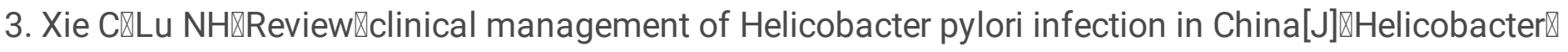
$2015 \varangle 20(1) \otimes 1-10 \rrbracket$

4. Warren JR, Marshall B. Unidentified curved bacilli on gastric epithelium in active chronic gastritis. Lancet 1983; 1: 1273-75.

5. Brown LM. Helicobacter pylori: epidemiology and routes of transmission. Epidemiol Rev 2000; 22: 283-97. 
6. Parsonnet J, Friedman GD, Vandersteen DP, et al. Helicobacter pylori infection and the risk of gastric carcinoma. N Engl J Med 1991; 325:1127-31.

7. Atherton JC. The pathogenesis of Helicobacter pylori-induced gastro-duldenal diseases. Annu Rev Pathol 2006;1:63-96.

8. Cave DR. How is Helicobater pylori transmitted? Gastroenterology 1997; 113(6 suppl): S9-14.

9. IARC Working Group on the Evaluation of Carcinogenic Risks to Humans. Schistosomes, liver flukes and Helicobacter pylori. IARC Working Group on the Evaluation of Carcinogenic Risks to Humans. Lyon, 7-14 June 1994. IARC Monogr Eval Carcinog Risks Hum 1994; 61: 1-241.

10. Malfertheiner P, Megraud F, O'Morain CA, Gisbert JP, Kuipers EJ6, Axon AT, Bazzoli F, Gasbarrini A, Atherton J, Graham DY, Hunt R, Moayyedi P, Rokkas T, Rugge M, Selgrad M, Suerbaum S, Sugano K, El-Omar EM; European Helicobacter and Microbiota Study Group and Consensus panel. Management of Helicobacter pylori infection-the Maastricht V/Florence Consensus Report. Gut.2017; 66(1):6-30.

11. Fallone CA, Chiba N, van Zanten SV, Fischbach L, Gisbert JP, Hunt RH, Jones NL, Render C, Leontiadis GI, Moayyedi P, Marshall JK. The Toronto Consensus for the Treatment of Helicobacter pylori Infection in Adults. Gastroenterology.2016; 151(1):51-69.

12. Fock KM, Katelaris P, Sugano K, Ang TL, Hunt R, Talley NJ, Lam SK, Xiao SD, Tan HJ, Wu CY, Jung HC, Hoang BH, Kachintorn U, Goh KL, Chiba T, Rani AA. Second Asia-Pacific Consensus Guidelines for Helicobacter pylori infection. J Gastroenterol Hepatol 2009; 24: 1587-1600 [PMID: 19788600 DOI: 10.1111/j.1440-1746.2009.05982.x]

13. World Gastroenterology Organisation. World Gastroenterology Organisation Global Guideline: Helicobacter pylori in developing countries. J Clin Gastroenterol 2011; 45: 383-388 [PMID: 21415768 DOI: 10.1097/MCG.0b013e31820fb8f6]

14. Malfertheiner P, Megraud F, O'Morain CA, Atherton J, Axon AT, Bazzoli F, Gensini GF, Gisbert JP, Graham DY, Rokkas T, El-Omar EM, Kuipers EJ. Management of Helicobacter pylori infection-the Maastricht IV/ Florence Consensus Report. Gut 2012; 61: 646-664 [PMID: 22491499 DOI: 10.1136/gutjnl-2012-302084].

15. Chey WD, Wong BC. American College of Gastroenterology guideline on the management of Helicobacter pylori infection. Am J Gastroenterol 2007; 102: 1808-1825 [PMID: 17608775 DOI: 10.1111/j.1572-0241.2007.01393.x]

16. Kuo YT, Liou JM, El-Omar EM, Wu JY, Leow AHR, Goh KL, Das R, Lu H, Lin JT, Tu YK, Yamaoka Y, Wu MS; Asian Pacific Alliance on Helicobacter and Microbiota. Primary antibiotic resistance in Helicobacter pylori in the Asia-Pacific region: a systematicreview and meta-analysis. Lancet Gastroenterol Hepatol. 2017; 2(10): 707-715.

17. Duck WM, Sobel J, Pruckler JM, Song Q, Swerdlow D, Friedman C, Sulka A, Swaminathan B, Taylor T, Hoekstra M, Griffin P, Smoot D, Peek R, Metz DC, Bloom PB, Goldschmidt S, Parsonnet J, Triadafilopoulos G, Perez-Perez GI, Vakil N, Ernst P, Czinn S, Dunne D, Gold BD. Antimicrobial 
resistance incidence and risk factors among Helicobacter pylori-infected persons, United States. Emerg Infect Dis. 2004 10(6): 1088-94.

18. Zeng M, Mao XH, Li JX, Tong WD, Wang B, Zhang YJ, Guo G, Zhao ZJ, Li L, Wu DL, Lu DS, Tan ZM, Liang HY, Wu C, Li DH, Luo P, Zeng H, Zhang WJ, Zhang JY, Guo BT, Zhu FC, Zou QM. Efficacy, safety, and immunogenicity of an oral recombinant Helicobacter pylori vaccine in children in China: a randomised, double-blind, placebo-controlled, phase 3 trial. Lancet. 2015;386 (10002): 1457-64.

19. Kang JK, Kim E, Kim KH, Oh SH. Association of Helicobacter pylori with gastritis and peptic ulcer diseases. Yonsei Med J.1991; 32(2): 157-68.

20. Schubert ML, Peura DA. Control of gastric acid secretion in health and disease. Gastroenterology 2008; 134:1842-60;

21. Schreiber S, Konradt M, Groll C, Scheid P, Hanauer G, Werling HO, Josenhans C \& Suerbaum S (2004) The spatial orientation of Helicobacter pylori in the gastric mucus. Proc Natl Acad Sci USA 101: 5024-5029.

22. Bhaskar KR, Garik P, Turner BS, Bradley JD, Bansil R, Stanley HE, LaMont JT. Viscous fingering of HCl through gastric mucin. Nature 1992; 360:458-61;

23. Williams SM, Chen YT, Andermann TM, Carter JE, McGee DJ, Ottemann KM. Helicobacter pylori chemotaxis modulates inflammation and bacterium-gastric epithelium interactions in infected mice. Infect Immun 2007; 75:3747-57;

24. Croxen MA, Sisson G, Melano R, Hoffman PS. The Helicobacter pylori chemotaxis receptor TIpB (HP0103) is required for $\mathrm{pH}$ taxis and for colonization of the gastric mucosa. $\mathrm{J}$ Bacteriol 2006; 188:2656- 65;

25. Li XX, Wong GL, To KF, Wong VW, Lai LH, Chow DK, Lau JY, Sung JJ, Ding C. Bacterial microbiota profiling in gastritis without Helicobacter pylori infection or non-steroidal anti-inflammatory drug use. PLoS One 2009; 4:e7985;

26. Bik EM, Eckburg PB, Gill SR, Nelson KE, Purdom EA, Francois F, Perez-Perez G, Blaser MJ, Relman DA. Molecular analysis of the bacterial microbiota in the human stomach. Proc Natl Acad Sci U S A 2006; 103:732-7;

27. Andersson AF, Lindberg M, Jakobsson H, Backhed F, Nyrén P, Engstrand L. Comparative analysis of human gut microbiota by barcoded pyrosequencing. PLoS One 2008;

28. Korecka A, Arulampalam V. The gut microbiome: scourge, sentinel or spectator? J Oral Microbiol $2012 ; 4$.

29. O'Hara AM, Shanahan F. The gut flora as a forgotten organ. EMBO Rep 2006; 7:688-93; PMID:16819463;

30. Kusters JG1, van Vliet AH, Kuipers EJ. Pathogenesis of Helicobacter pylori infection. Clin Microbiol Rev. 2006; 19(3): 449-90.

31. Lamouliatte H. Adjuvant therapy for Helicobacter pylori eradication: role of lansoprazole in clinical studies[J]. J Clin Gastroenterol, 1995, 20(Suppl 1):S28-31 
32. Goh KL, Parasakthi N, Peh SC, et al. Prolonged treatment with omeprazole does not improve the eradication rate of Helicobacter pylori infection-a short report [corrected]. Singapore Med J. 1995, 36(6):619-620

33. Meining $A$, Wick $M$, Miehlke $S$, et al $₫$ The presence of immunoglobulins in the gastric juice of patients

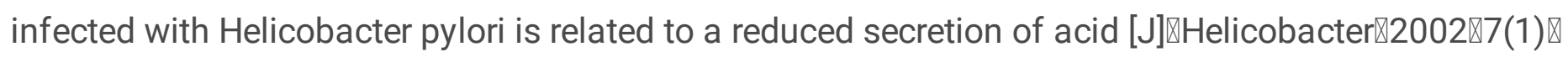
67-70区

34. Iwahi T, Satoh H, Nakao M, et al. Lansoprazole, a novel benzimidazole proton pump inhibitor, and its related compounds have selective activity against Helicobacter pylori[J]. Antimicrob Agents Chemother, 1991, 35(3):490-496

35. O'Toole, P. W., M. C. Lane, and S. Porwollik. 2000. Helicobacter pylori motility. Microbes Infect. 2:1207-1214.

36. Bugaytsova JA, Björnham O, Chernov YA, Gideonsson P, Henriksson S, Mendez M, Sjöström R, Mahdavi J, Shevtsova A, Ilver D, Moonens K, Quintana-Hayashi MP, Moskalenko R, Aisenbrey C, Bylund G, Schmidt A, Åberg A, Brännström K, Königer V, Vikström S, Rakhimova L, Hofer A, Ögren J, Liu H, Goldman MD, Whitmire JM, Ådén J, Younson J, Kelly CG, Gilman RH, Chowdhury A, Mukhopadhyay AK, Nair GB, Papadakos KS, Martinez-Gonzalez B, Sgouras DN, Engstrand L, Unemo M, Danielsson D, Suerbaum S, Oscarson S, Morozova-Roche LA, Olofsson A, Gröbner G, Holgersson J, Esberg A, Strömberg N, Landström M, Eldridge AM, Chromy BA, Hansen LM, Solnick JV, Lindén SK, Haas R, Dubois A, Merrell DS, Schedin S, Remaut H, Arnqvist A, Berg DE, Borén T. Helicobacter pylori Adapts to Chronic Infection and Gastric Disease via pH-Responsive BabA-Mediated Adherence. Cell Host Microbe. 2017; 21(3): 376-389.

37. Bren, A. \& Eisenbach, M. (2000) J. Bacteriol. 182, 6865-6873.

38. D. Scott Merrell, Maria L. Goodrich, Glen Otto, Lucy S. Tompkins, and Stanley Falkow. pH-Regulated Gene Expression of the Gastric Pathogen Helicobacter pylori. INFECTION AND IMMUNITY, 2003, p. 3529-3539

\section{Table 1}

Table 1 Characteristics of the patients

\begin{tabular}{llll}
\hline Parameter & Control group $(\mathrm{n}=37)$ & $\begin{array}{l}\text { Intervention group } \\
(\mathrm{n}=31)\end{array}$ & $P$-value \\
\hline Gender $(\mathrm{M} / \mathrm{F})$ & $20 / 27$ & $19 / 12$ & 0.548 \\
Age, mean \pm SD & $53.2 \pm 11.7$ & $55.8 \pm 12.8$ & 0.256 \\
$\mathrm{pH}$ value of gastric juice, mean \pm SD & $1.59 \pm 0.76$ & $6.70 \pm 1.42$ & $<0.001$ \\
\hline
\end{tabular}




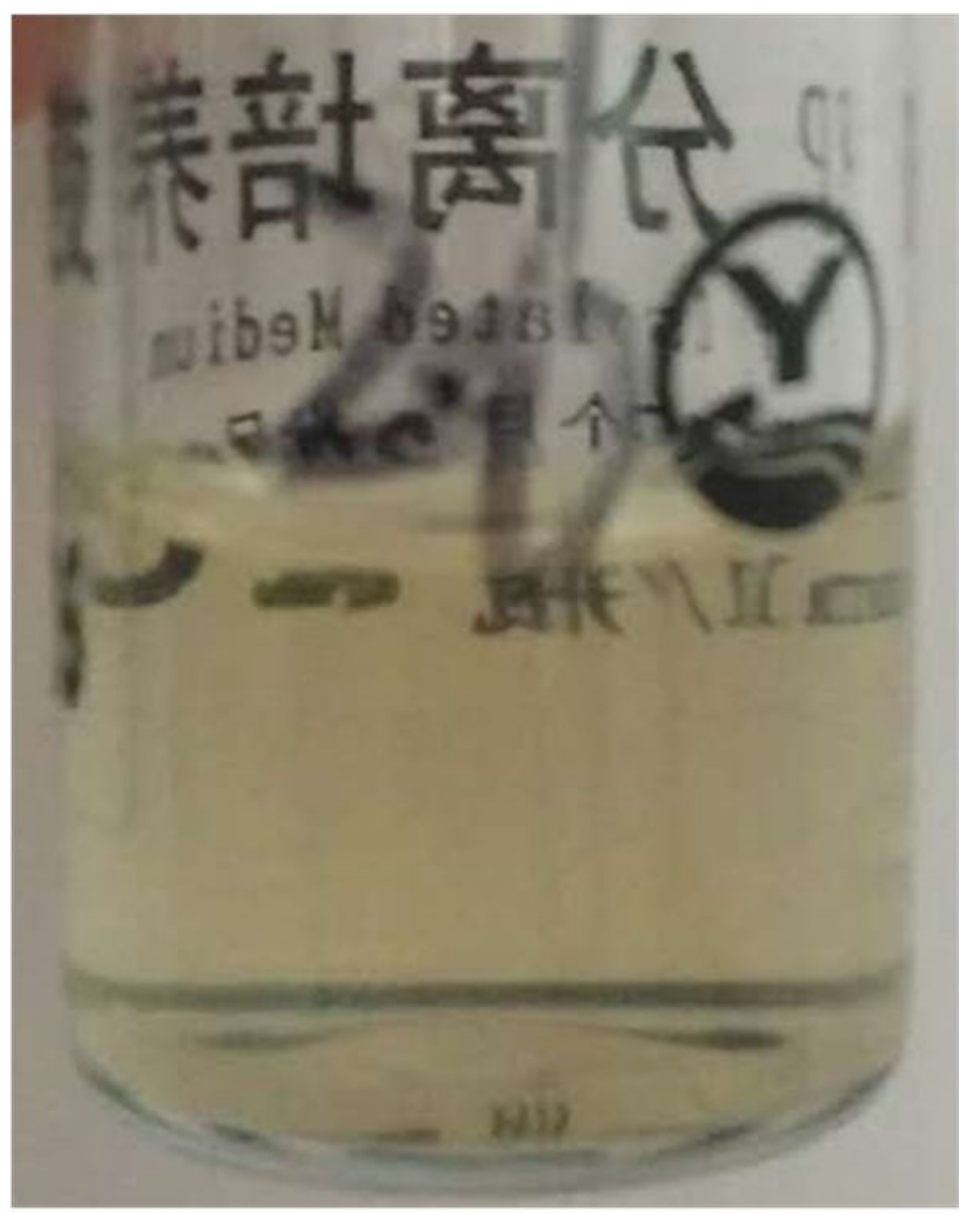

(A)

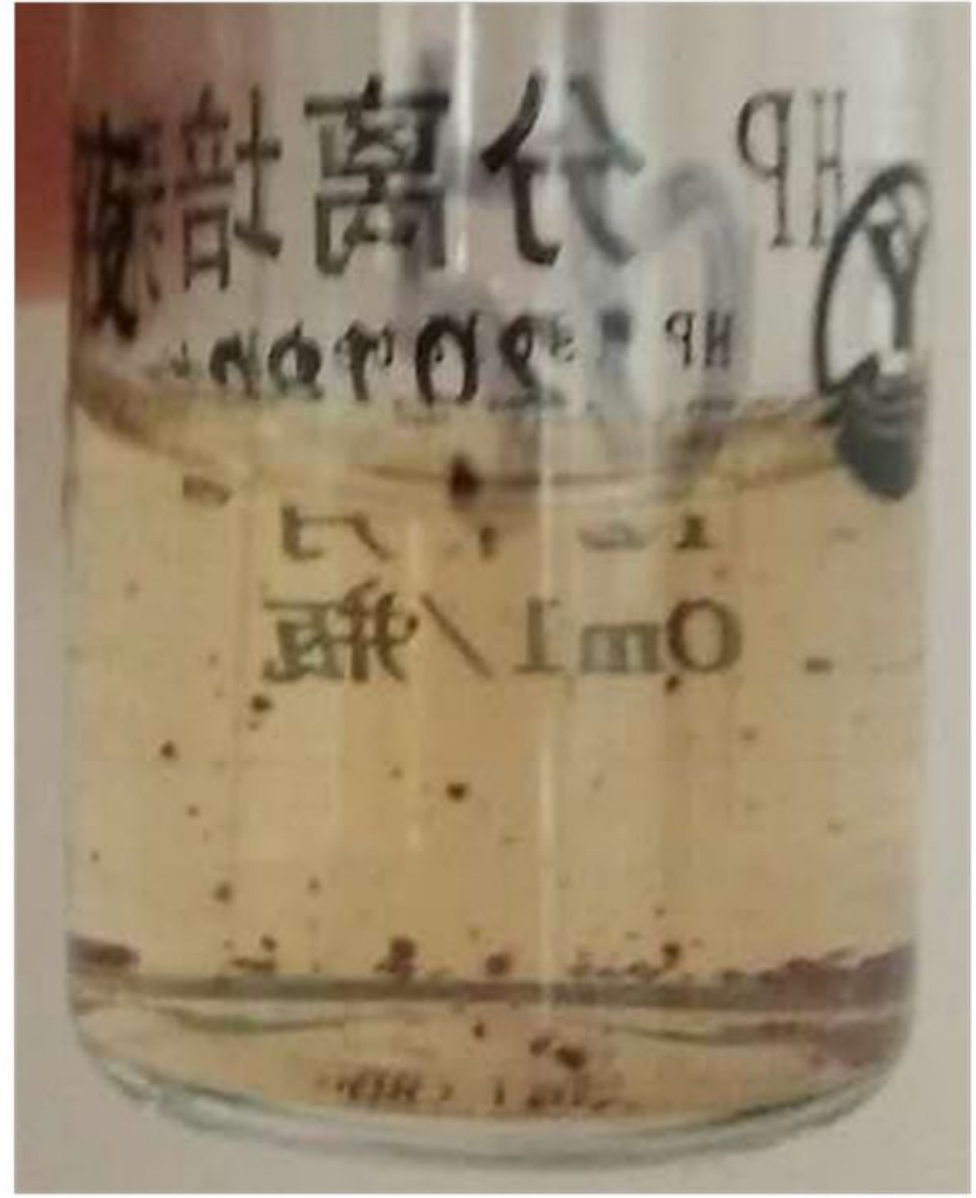

(B)

\section{Figure 1}

Culture liquid turbidity and red suggesting $\mathrm{H}$. pylori growth. (A) Negative result. (B) Positive result. 

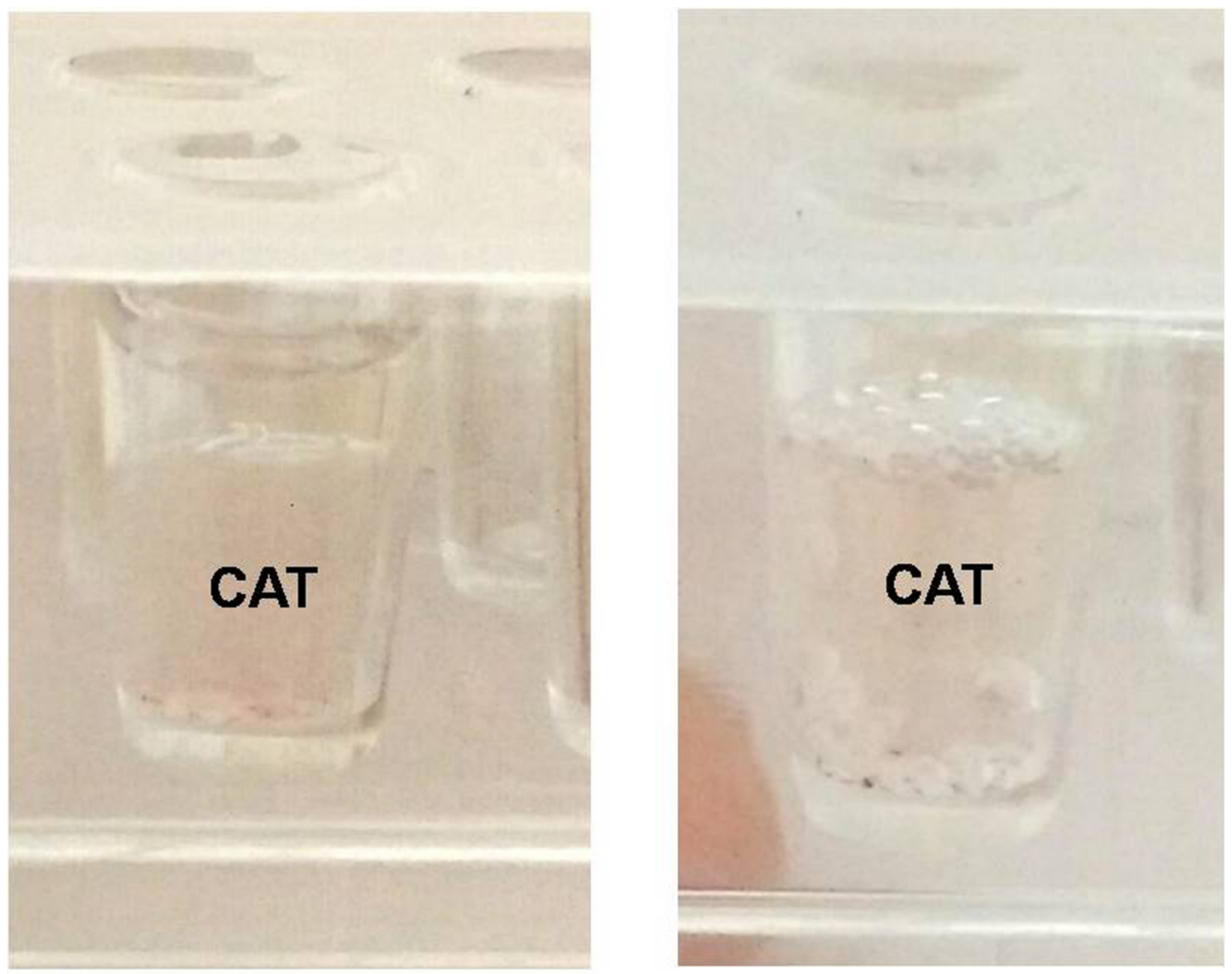

\section{(A)}

(B)

Figure 2

$\mathrm{H}$. pylori can generate catalase which decompose H2O2 and released bubbles in micropore labeled 'CAT'. Bubbles can be seen in CAT micropore was identified as H. pylori positive. (A) Negative result. (B) Positive result. 


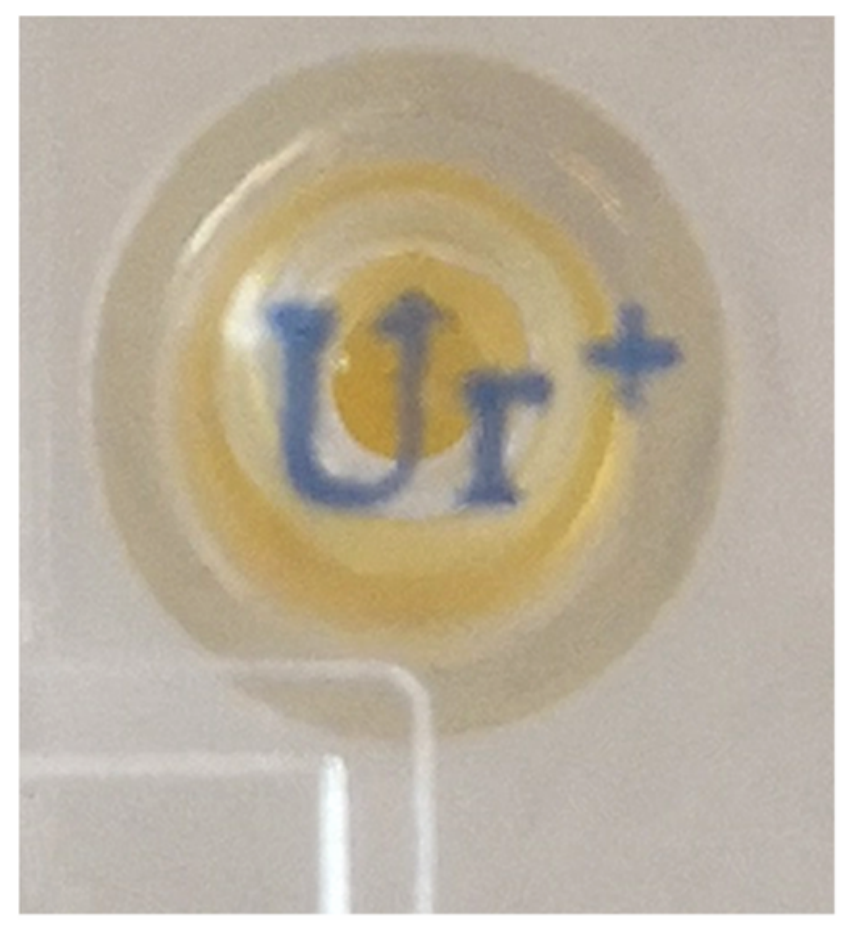

(A)

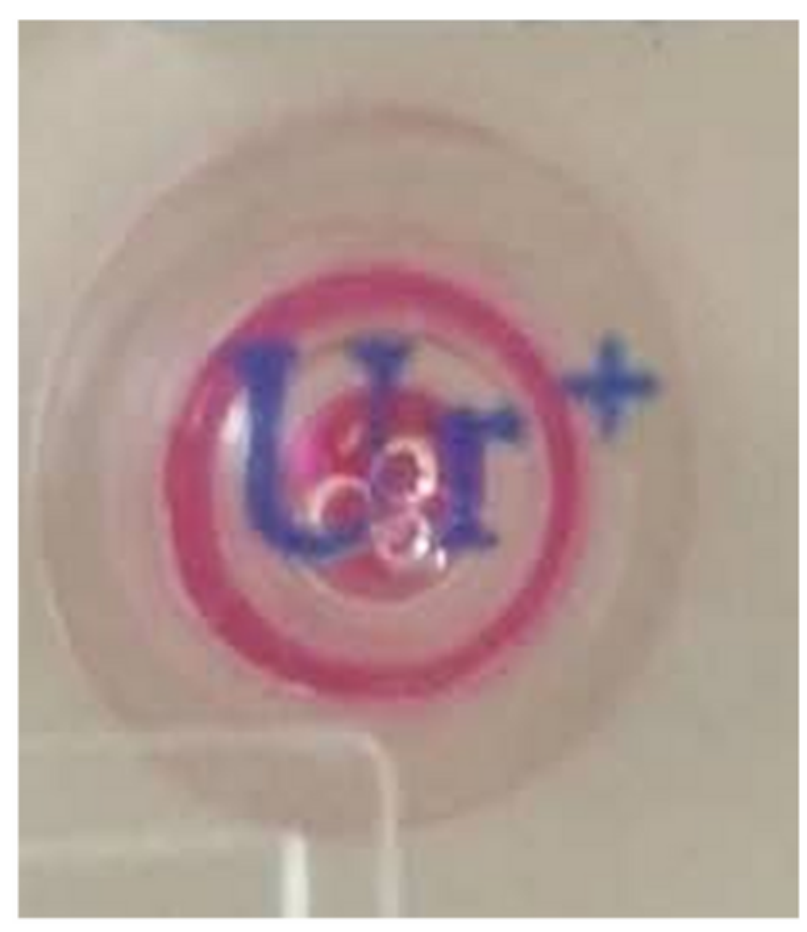

(B)

\section{Figure 3}

H. pylori can generate urease which decompose the urea, released ammonia in micropore labeled 'Urt', and the ammonia can turned the phenol red from yellow to red colour. The Ur+ micropore turned from yellow to red colour was identified as H. pylori positive. (A) Negative result. (B) Positive result.

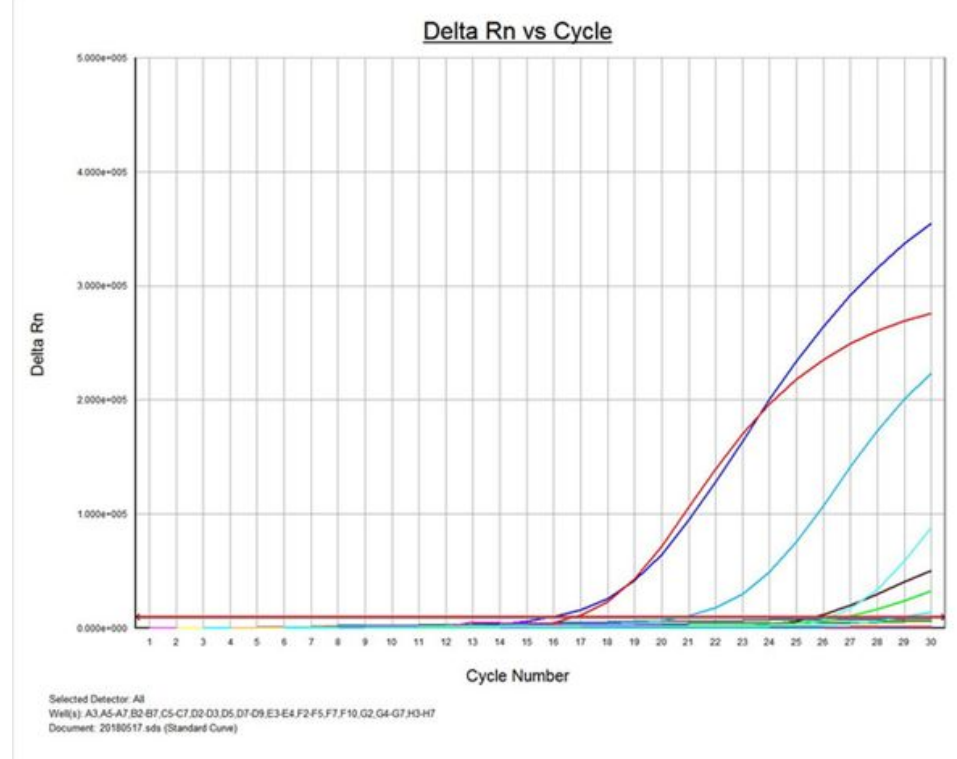

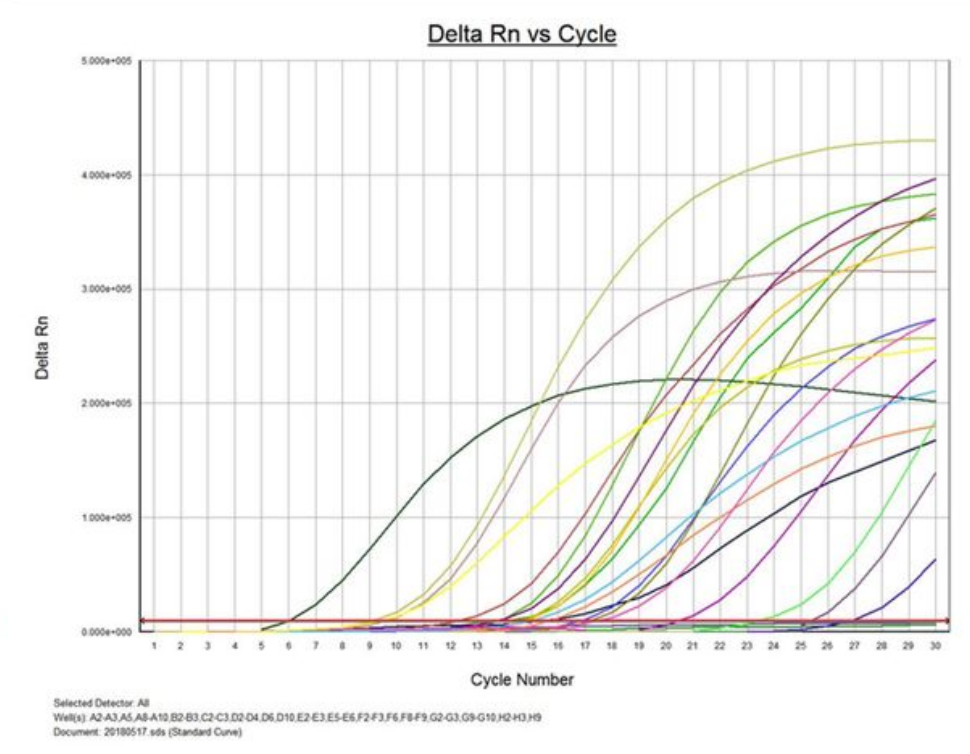

Intervention group

Control group

\section{Figure 4}


Comparison of gastric fluid PCR for H. pylori with and without PPI. The positive frequency was higher in PPI intervention group than that in Control group $(P<0.001)$.

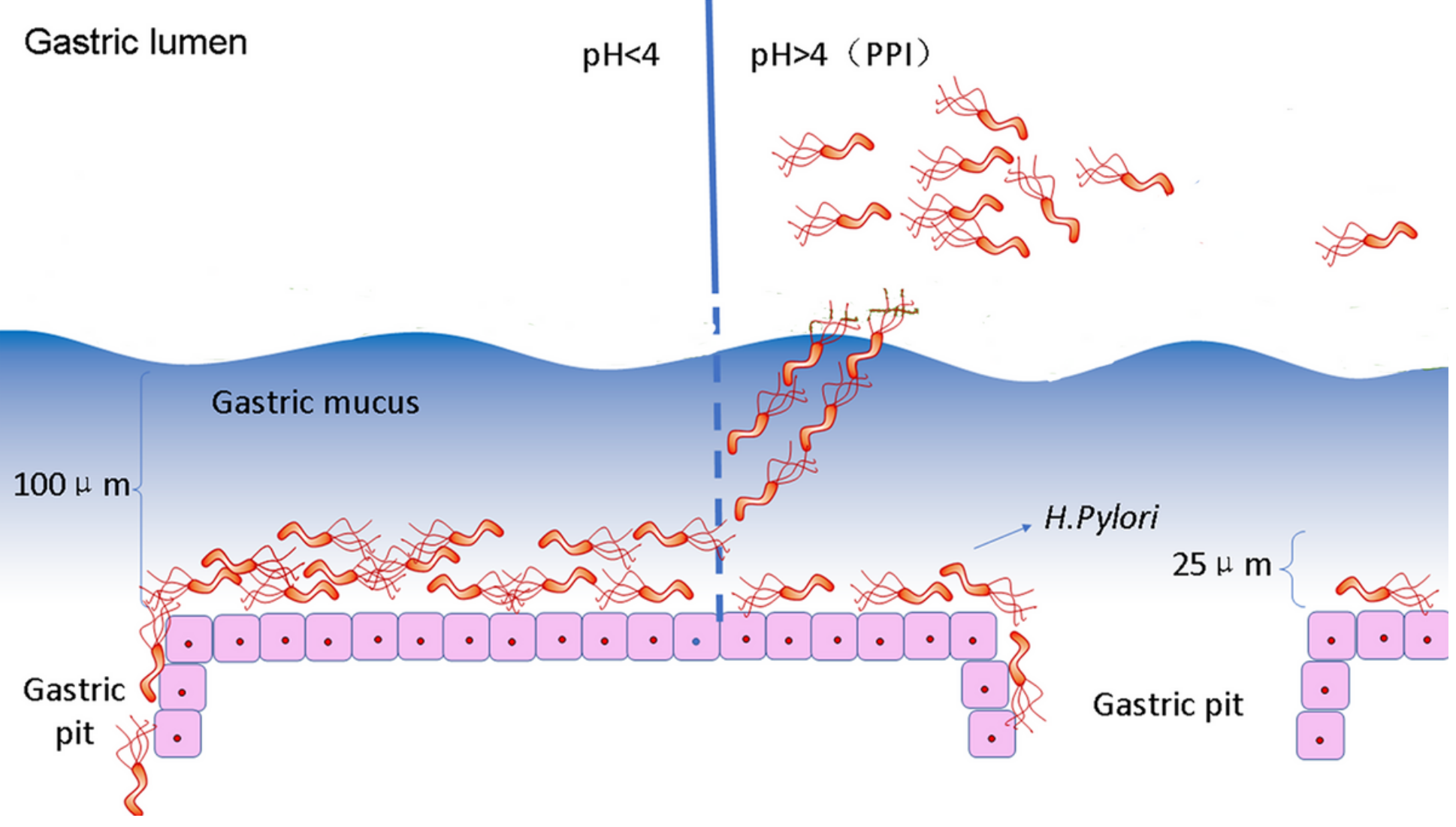

\section{Figure 5}

The movement characteristics of H. pylori under PPI intervention and the mechanisms of action of PPI, antibiotics and probiotics. 